\title{
PRENATAL DIAGNOSIS, MANAGEMENT AND OUTCOME OF FETAL URETERO-PELVIC JUNCTION OBSTRUCTION
}

\author{
G. Bosman ${ }^{\dagger}$ A. Reuss, ${ }^{\dagger}$ J. M. NiJMAN ${ }^{\ddagger}$ and J. W. WLAdIMIROFF ${ }^{\dagger}$ \\ ${ }^{\dagger}$ Departments of Obstetrics and Gynaecology and 'Pediatric Urology, Erasmus University, \\ Medical School Rotterdam, The Netherlands
}

(Received 15 February 1990; in final form 20 August 1990)

\begin{abstract}
Prenatal diagnosis, management and outcome were studied retrospectively in 24 cases of unilateral and bilateral uretero-pelvic junction obstruction (UPJO). Moderate-to-marked pelvic dilatation was documented in 19 out of 24 cases. The low morbidity and mortality observed in this study are probably determined by the late (third trimester) detection of UPJO, resulting in an underestimation of the prevalence of more severe renal pathology. Amniotic fluid was increased in 4 out of 14 cases of unilateral UPJO and in 5 out of 10 cases of bilateral UPJO, the underlying mechanism of which is still unclear. There was no oligohydramnios. The incidence of extrarenal structural pathology was low, i.e., 3 out of 24 cases. A close agreement could be demonstrated between pre- and postnatal sonographic grading of pelvic dilatation. However, postnatal ultrasonic grading of pelvic dilatation correlated poorly with the degree of functional obstruction as determined by IVP and lasix renography. Despite the severity of pelvic dilatation in the majority of cases, enlarged kidneys were revealed by postnatal clinical examination in only three instances, underlining the importance of prenatal sonographic detection of UPJO.
\end{abstract}

Key Words: Uretero-pelvic junction obstruction, Diagnostic ultrasound.

\section{INTRODUCTION}

The potential of real-time ultrasound in the detection of fetal structural defects is now well established. Accurate identification of fetal kidneys by transabdominal ultrasound is possible from 12 weeks of gestation onwards. Fetal urinary bladder filling can be visualized as early as 12 weeks. Whereas both conservative and active management have been propagated in the presence of lower urinary tract obstruction, relatively little attention has been paid to management and outcome of prenatally diagnosed high-level urinary tract obstruction, in particular uretero-pelvic junction obstruction (UPJO).

This paper presents a retrospective analysis of fetal unilateral and bilateral UPJO with emphasis on prenatal sonographic diagnosis, pre- and postnatal management and outcome.

\section{MATERIAL AND METHODS}

Between January 1983 and January 1989, a total of 91 women was seen in our Ultrasound Unit be-

Address correspondence to: J. W. Wladimiroff, M.D., Ph.D., Professor of Obstetrics and Gynaecology, Academic Hospital Rotterdam-Dijzkigt, Erasmus University Rotterdam, Dr. Molewaterplein 40, 3015 GD Rotterdam, The Netherlands. cause of fetal obstructive uropathy. In 24 of these women, unilateral or bilateral fetal UPJO was diagnosed. Ultrasound examinations were performed using a real-time mechanical sector scanner (Diasonics $\mathrm{CV} 400$ ) with a $5 \mathrm{MHz}$ transducer. Gestational age was calculated from the last menstrual period and/or early sonographic measurement of the fetal biparietal diameter. In each fetus, the following sonographic features were documented:

1. Size of renal pelvis. Dilatation was classified according to pelvic diameter and calyceal dilatation as first described by Grignon et al. (1986) with the exception that grades 4 and 5 were combined (grade 4):

Grade 1: pyelum $<1 \mathrm{~cm}$, no calyceal dilatation (this was still considered physiological);

Grade 2: pyelum $1.0-1.5 \mathrm{~cm}$, no calyceal dilatation;

Grade 3: pyelum $>1.5 \mathrm{~cm}$, moderate calyceal dilatation;

Grade 4: pyelum $>1.5 \mathrm{~cm}$, marked calyceal dilatation.

2. Amount of amniotic fluid (normal, reduced or increased).

3. Presence of associated abnormalities. 
As soon as the diagnosis UPJO was made, obstetric management was discussed by the perinatal team, consisting of an obstetrician, pediatric urologist, neonatologist and sonographist. Neonatal follow-up was available in 22 of 23 live born infants; autopsy was carried out in one case of intrauterine death. Postnatally, ultrasound classification of the degree of pelvic dilatation was identical to that employed during the prenatal period. Serum creatinine levels were determined to evaluate postnatal renal function. Functional outflow obstruction of the postnatal renal pelvis as estimated on intravenous pyelogram (IVP) and lasix renography was classified as: 0 absent; 1 mild; 2 moderate; 3 severe.

\section{RESULTS}

\section{Unilateral UPJO}

UPJO was prenatally diagnosed as unilateral in 14 cases (Table 1). Gestational age at diagnosis varied between 25 and 37 weeks (mean 32.6 weeks). Most cases $(n=8)$ were diagnosed during routine sonography. In one case, there was a positive family history of urinary tract anomalies (sibling with posterior urethral valves). In five pregnancies, abnormal obstetric findings (large or small-for-dates uterus; abnormal fetal position) led to the ultrasound scan. Grade 4 pelvic dilatation was documented in 13 cases and grade 3 pelvic dilatation in the remaining case. Amniotic fluid volume was increased in four cases; there was no oligohydramnios. Ultrasound examination did not reveal any major associated anomalies. Ex- pectant management through serial scanning was employed. No further deterioration of the sonographic findings was seen.

Thirteen infants were delivered at term with a birth weight according to gestational age (Kloosterman 1970). One small-for-gestational age infant was delivered at 35 weeks of gestation following premature rupture of the membranes. The sex ratio (male/ female) was 10:4. An enlarged kidney was palpated in two of the newborns. Serum creatinine levels were normal in all instances (mean $30.4 \mu \mathrm{mol} / \mathrm{L}$; range 21-38 $\mu \mathrm{mol} / \mathrm{L})$. Associated anomalies were documented in two cases (extra left thumb; pyloric stenosis).

In three infants with prenatally diagnosed unilateral grade 4 UPJO, there was also grade 2 pelvic dilatation on the contralateral side after birth. Complete agreement between pre- and postnatal sonographic grading of pelvic dilatation existed in the remaining 11 cases of unilateral UPJO. No correlation existed between the sonographic grading and the degree of functional outflow obstruction, as determined with lasix renography.

Unilateral pyeloplasty was carried out in seven infants with unilateral grade 4 UPJO and two cases of bilateral grade 2/4 UPJO. Because of a nonfunctional kidney, nephrectomy was performed in two infants with unilateral grade 4 UPJO. Of the remaining two cases of unilateral UPJO, one is still awaiting pyeloplasty and one was lost to follow-up at the age of six months. In the infant with grade 3 unilateral pelvic dilatation, there was a moderate outflow obstruction

Table 1. Prenatal and postnatal findings in 14 cases of unilateral uretero-pelvic junction obstruction.

\begin{tabular}{|c|c|c|c|c|c|c|c|c|c|c|c|}
\hline \multirow{2}{*}{$\begin{array}{c}\text { Patient } \\
\text { no. }\end{array}$} & \multirow{2}{*}{$\begin{array}{l}\text { Gestational } \\
\text { age (wks) } \\
\text { at diagnosis }\end{array}$} & \multirow{2}{*}{$\begin{array}{l}\text { Amniotic } \\
\text { fluid } \\
\text { volume }\end{array}$} & \multicolumn{2}{|c|}{$\begin{array}{l}\text { Prenatal } \\
\text { sono- } \\
\text { graphic } \\
\text { findings }\end{array}$} & \multirow{2}{*}{$\begin{array}{c}\text { Gestational } \\
\text { age (wks) } \\
\text { at delivery }\end{array}$} & \multirow{2}{*}{$\begin{array}{c}\text { Birth } \\
\text { weight } \\
\text { gr }\end{array}$} & \multicolumn{2}{|c|}{$\begin{array}{l}\text { Postnatal } \\
\text { findings }\end{array}$} & \multirow[b]{2}{*}{ Management } & \multirow[b]{2}{*}{ Outcome } & \multirow{2}{*}{$\begin{array}{c}\text { Creatinine } \\
(\mu \mathrm{mol})\end{array}$} \\
\hline & & & LK & RK & & & LK & RK & & & \\
\hline 1 & 33 & $\mathbf{N}$ & & gr4 & 35 & 1820 & gr2 & gr4 & R pyeloplasty & NF-MO & 26 \\
\hline 2 & 33 & $\mathbf{N}$ & & gr3 & 41 & 3570 & & $\mathrm{gr} 3$ & No surgery & NF-MO & - \\
\hline 3 & 32 & $N$ & & gr4 & 38 & 3380 & gr2 & gr4 & R pyeloplasty & NF-MO & 24 \\
\hline 4 & 33 & $\mathbf{R}$ & $\mathrm{gr} 4$ & & 40 & 3950 & $\mathrm{gr} 4$ & & $\begin{array}{l}\text { Awaiting } \\
\text { pyeloplasty }\end{array}$ & NF-SO & 28 \\
\hline 5 & 24 & $\mathbf{N}$ & & gr4 & 39 & 3800 & & $g r 4$ & Lost to followup & & 31 \\
\hline 6 & 26 & $\mathbf{N}$ & gr4 & & 40 & 3800 & $\mathrm{gr} 4$ & & L pyeloplasty & NF-MO & 25 \\
\hline 7 & 36 & $N$ & gr4 & & 39 & 3740 & $\mathrm{gr} 4$ & & L pyeloplasty & NF-NO & 36 \\
\hline 8 & 37 & $\mathbf{N}$ & gr4 & & 39 & 3420 & $\mathrm{gr} 4$ & & L pyeloplasty & NF-MO & 35 \\
\hline 9 & 37 & $\mathbf{N}$ & gr4 & & 41 & 4700 & gr4 & & L nephrectomy & NF & 38 \\
\hline 10 & 36 & $\mathbf{R}$ & & gr4 & 39 & 3850 & & gr4 & R pyeloplasty & NF-NO & 34 \\
\hline 11 & 25 & $\mathbf{R}$ & gr4 & & 37 & 3000 & gr4 & $\mathrm{gr} 2$ & L nephrectomy & NF & 28 \\
\hline 12 & 33 & $\mathbf{N}$ & $\mathrm{gr} 4$ & & 40 & 3880 & $\mathrm{gr} 4$ & & L pyeloplasty & NF-NO & 34 \\
\hline 13 & 34 & $\mathbf{R}$ & & gr4 & 37 & 3500 & & gr4 & $R$ pyeloplasty & NF-MO & 34 \\
\hline 14 & 32 & $\mathbf{N}$ & gr4 & & 40 & - & gr4 & & L pyeloplasty & NF-MO & 33 \\
\hline
\end{tabular}

$\mathrm{N}=$ normal; $\mathrm{R}=$ raised; $\mathrm{LK}=$ left kidney; $\mathrm{RK}=$ right kidney; $\mathrm{NF}=$ normal function; $\mathrm{NO}=$ no obstruction; $\mathrm{MO}=$ moderate obstruction; $\mathrm{SO}$ $=$ serious obstruction. 
Table 2. Prenatal and postnatal findings in 10 cases of bilateral uretero-pelvic junction obstruction.

\begin{tabular}{|c|c|c|c|c|c|c|c|c|c|c|c|}
\hline \multirow{2}{*}{$\begin{array}{l}\text { Patient } \\
\text { no. }\end{array}$} & \multirow{2}{*}{$\begin{array}{c}\text { Gestational } \\
\text { age (wks) } \\
\text { at diagnosis }\end{array}$} & \multirow{2}{*}{$\begin{array}{l}\text { Amniotic } \\
\text { fluid } \\
\text { volume }\end{array}$} & \multicolumn{2}{|c|}{$\begin{array}{l}\text { Prenatal } \\
\text { sono- } \\
\text { graphic } \\
\text { findings }\end{array}$} & \multirow{2}{*}{$\begin{array}{c}\text { Gestational } \\
\text { age (wks) } \\
\text { at delivery }\end{array}$} & \multirow{2}{*}{$\begin{array}{c}\text { Birth } \\
\text { weight } \\
\text { gr }\end{array}$} & \multicolumn{2}{|c|}{$\begin{array}{l}\text { Postnatal } \\
\text { findings }\end{array}$} & \multirow[b]{2}{*}{ Management } & \multirow[b]{2}{*}{ Outcome } & \multirow{2}{*}{$\begin{array}{c}\text { Creatinine } \\
(\mu \mathrm{mol})\end{array}$} \\
\hline & & & LK & RK & & & LK & RK & & & \\
\hline 1 & 25 & $\mathrm{~N}$ & $\mathrm{gr} 3$ & $\mathrm{gr} 3$ & 39 & 3470 & $\mathrm{gr} 3$ & $\mathrm{gr} 3$ & Expectant & NF-PD & 26 \\
\hline 2 & 27 & $\mathrm{~N}$ & $\mathrm{gr} 2$ & $\mathrm{gr} 2$ & 39 & 3120 & $\mathrm{gr} 2$ & $\mathrm{gr} 2$ & Expectant & $\mathrm{NF} / \mathrm{NO}$ & 27 \\
\hline 3 & 29 & $\mathrm{~N}$ & $\mathrm{gr} 2$ & $\mathrm{gr} 3$ & 37 & 3275 & $\mathrm{gr} 2$ & gr3 & Expectant & $\mathrm{NF} / \mathrm{NO}$ & 28 \\
\hline 4 & 34 & $\mathbf{R}$ & gr3 & $\mathrm{gr} 2$ & 36 & 2690 & $\mathrm{gr} 3$ & $\mathrm{gr} 2$ & Expectant & NF-MO & 36 \\
\hline 5 & 31 & $\mathbf{R}$ & $\mathrm{gr} 4$ & gr4 & 38 & 2985 & $\mathrm{gr} 4$ & $\mathrm{gr} 4$ & Expectant & NF-MO & 21 \\
\hline 6 & 21 & $\mathbf{R}$ & $\mathrm{gr} 4$ & $\mathrm{gr} 4$ & 22 & - & $\mathrm{gr} 4$ & gr4 & TOP & NF-MO & - \\
\hline 7 & 25 & $\mathbf{N}$ & gr2 & $\mathrm{gr} 2$ & 41 & 2390 & $\mathrm{gr} 3$ & - & L pyeloplasty & NF-SD & 27 \\
\hline 8 & 31 & $\mathbf{R}$ & $\mathrm{gr} 4$ & $\mathrm{gr} 4$ & 37 & 3000 & $\mathrm{gr} 2$ & $\mathrm{gr} 2$ & $\begin{array}{l}\text { Expectant } \\
\text { (Noonan } \\
\text { syndrome) }\end{array}$ & NF-MO & 26 \\
\hline 9 & 35 & $\mathbf{R}$ & $\mathrm{gr} 4$ & $\mathrm{gr} 2$ & 37 & 3590 & $\mathrm{gr} 3$ & $\mathrm{gr} 2$ & Expectant & NF-MO & 37 \\
\hline 10 & 36 & $\mathrm{~N}$ & $\mathrm{gr} 3$ & $\mathrm{gr} 2$ & 41 & 3920 & $\mathrm{grl}$ & grl & Expectant & NF-NO & 39 \\
\hline
\end{tabular}

$\mathrm{N}=$ normal; $\mathrm{R}=$ raised; $\mathrm{LK}=$ left kidney; $\mathrm{RK}=$ right kidney; $\mathrm{NF}=$ normal function; $\mathrm{NO}=$ no obstruction; $\mathrm{SD}=$ slight dilatation; $\mathrm{MO}=$ moderate obstruction; $P D=$ persistent dilatation; $T O P=$ termination of pregnancy.

which did not justify surgery. All 13 infants available at one-year follow-up were alive and well at that stage.

\section{Bilateral UPJO}

Bilateral UPJO was established prenatally in 10 cases (Table 2). Gestational age at diagnosis varied between 21 and 36 weeks (mean 29.7 weeks). In eight cases, the diagnosis UPJO was made during routine sonography. In the remaining two cases, there was a positive family history of a unilateral duplex system in a second degree relative and one case of a largefor-dates uterus. Bilateral grade 4 pelvic dilatation was diagnosed in three cases, bilateral grade 3 pelvic dilatation in one case and bilateral grade 2 pelvic dilatation in two cases. The remaining four cases displayed combinations of grade 2 to grade 4 pelvic dilatation. Amniotic fluid volume was increased in five instances, including the three cases of bilateral grade 4 pelvic dilatation. There was no oligohydramnios. A ventricular septal defect was suspected in one case of bilateral grade 4 dilatation. Here, progressive massive hydronephrosis resulted in parental request for pregnancy termination at 22 weeks of gestation. Postmortem examination confirmed the renal findings; no cardiac abnormalities were found. All remaining nine pregnancies were managed conservatively and progressed to term uneventfully without sonographic signs of further deterioration of UPJO.

Birth weights were according to gestational age (Kloosterman 1970), except in one infant which was small-for-dates. The sex ratio (male/female) was 9:1. Enlarged kidneys were palpated in only one of the newborns. Serum creatinine levels were nearly always within the normal range (mean $38.6 \mu \mathrm{mol} / \mathrm{L}$, range $7-59 \mu \mathrm{mol} / \mathrm{L}$ ). Associated anomalies were established in three cases (VSD, $N=2$; Noonan syndrome). The degree of pelvic dilatation was confirmed by postnatal sonography in seven cases. One prenatally diagnosed bilateral grade 2 pelvic dilatation was postnatally classified as unilateral grade 3 dilatation. In one other infant (with Noonan syndrome), prenatally diagnosed bilateral grade 4 was postnatally classified as bilateral grade 2 . Normal renal anatomy instead of bilateral grade $2 / 3$ pelvic dilatation was established in the remaining case. Also, here, there was no correlation between the sonographic grading and the degree of functional outflow obstruction.

Pyeloplasty was performed in the infant with unilateral grade 3 pelvic dilatation. In the remaining seven infants with bilateral UPJO, no surgery was needed. Apart from the infant with Noonan syndrome, all other surviving infants were alive and well at the age of one year.

\section{DISCUSSION}

UPJO is the most common cause of hydronephrosis in the neonate and the child (Johnston et al. 1977). The pathogenesis of this condition is unknown. Anatomical causes for UPJO are only seen in a fraction of patients. In most instances of UPJO, the junction is anatomically patent to the passage of a probe; the problem, therefore, seems to be of a functional nature. Abnormal development of the interwoven muscularis of the ureter would impair bolus formation and propulsion of urine. Other possible causes of the picture of a dilated system include normal variants, such as extrarenal pelvis. Prenatal ul- 
trasound correctly graded pelvic dilatation over $90 \%$ of cases of UPJO.

Of interest is that both in unilateral and bilateral UPJO there was no further increase in pelvic dilatation with advancing gestational age. Marked pelvic dilatation was nearly always associated with term delivery of a normal weight infant. On the other hand, our data also demonstrate that during pregnancy spontaneous resolution of fetal pelvic dilatation secondary to UPJO did not occur. The incidence (12\%) of extrarenal pathology associated with UPJO is low compared to that reported for low-level obstructive uropathies (40\%) (Reuss et al. 1988). In the present study, all three extrarenal anomalies (sixth digit, pyloric stenosis) had been missed including the Noonan syndrome which is characterized by webbing of the neck, pectus excavatum, cryptorchidism and pulmonary stenosis. There was one false positive diagnosis of a ventricular septal defect at 22 weeks of gestation. This points at the limited value of prenatal ultrasound in diagnosing or excluding these types of anomalies. There were no cases of oligohydramnios. Amniotic fluid volume was even increased in $29 \%$ of unilateral UPJO and in 50\% of bilateral UPJO, the underlying mechanism of which is still unclear.

Despite the severity of pelvic dilatation in nearly all unilateral and most bilateral cases of UPJO, postnatal clinical examination revealed an enlarged kidney in only three instances. This means that the majority of the kidneys requiring surgical decompression would not have been detected with postnatal clinical examination alone. This stresses the importance of prenatal ultrasound detection of UPJO, since it will improve neonatal clinical management allowing early repair and maximum salvage of affected kidneys. Although timely surgical intervention has undoubtedly contributed to the favourable outcome observed at the age of one year, it should be realised that the minimal morbidity and mortality in our series may also have been determined by case selection. Bilateral UPJO was present in $50 \%$ of cases and was generally detected late in pregnancy. This may have resulted in an underestimation of the prevalence of severe bilateral renal disease.

Whereas prenatal sonographic diagnosis coincided with postnatal ultrasound findings in nearly every instance, a poor correlation existed between postnatal anatomic grading of pelvic dilatation by ultrasound and degree of functional outflow obstruction as determined by IVP and lasix-renography.
Exact methods of measuring fetal renal function are not yet available. Ultrasound does allow noninvasive measurement of fetal urine production (Campbell et al. 1973; Wladimiroff and Campbell 1974). Hourly fetal urinary production rates, however, are only a crude reflection of fetal diuresis and should not be used under pathological circumstances. Also, biochemical studies in fetal urine were introduced as a measure of fetal renal function (Glick et al. 1985; Appelman and Golbus 1986). Fetal urine was obtained through ultrasound-guided bladder needling for urinary electrolyte determination. Separate sampling from each kidney rather than the bladder should be considered in the presence of UPJO. However, the interpretation of fetal urinary electrolytes as a prognostic indication of good or poor renal function still needs to be clarified (Reuss et al. 1987). In the presence of normal or increased amniotic fluid volume, as was the case in the present study, assessment of fetal renal function would probably not have affected obstetric management.

It can be concluded that prenatal ultrasound is helpful in detecting UPJO in cases which would have gone undetected at postnatal clinical examination. Pre- and postnatal sonographic grading of pelvic dilatation is, however, not informative of the degree of functional outflow obstruction.

\section{REFERENCES}

Appelman, Z.; Golbus, M. S. The management of fetal urinary tract obstruction. Clin. Obstet. Gynecol. 29:483-489; 1986.

Campbell, S.; Wladimiroff, J. W.; Dewhurst, C. J. The antenatal measurement of fetal urine production. J. of Obstet. Gyn. of the Brit. Commonwealth 80:680-686; 1973.

Glick, R. L.; Harrison, M. R.; Golbus, M. S.; Adzick, N. S.; Filly, R. A.; Callen, P. W.; Mahoney, B. S.; Anderson, R. L.; Delorimier, A. A. Management of the fetus with congenital hydronephrosis: Prognosis, criteria and selection for treatment. J. Pediatr. Surg. 20:376-387; 1985.

Grignon, A.; Filion, R.; Filiatraut, D.; Robitaille, P.; Homsy, Y.; Boutin, H.; Leblond, R. Urinary tract dilatation in utero: Classification and clinical applications. Radiology 160:645-647; 1986.

Johnston, J. H.; Evans, J. P.; Glassberg, K. I.; Shapiro, S. R. Pelvic hydronephrosis in children: A review of 219 personal cases. J. Urol. 117:97-101; 1977.

Kloosterman, G. J. On intrauterine growth. Int. J. Gynaecol. Obstet. 8:895-901; 1970.

Reuss, A.; Wladimiroff, J. W.; Niermeijer, M. F. Antenatal diagnosis of renal tract anomalies by ultrasound. Pediatr. Nephrol. 1:546-552; 1987.

Reuss, A.; Wladimiroff, J. W.; Stewart, P. A.; Scholtmeijer, R. J. Non-invasive management of fetal obstructive uropathy. Lancet 22:949-952; 1988.

Wladimiroff, J. W.; Campbell, S. Fetal urine production rates in normal and complicated pregnancy. Lancet i:151-154; 1974 